\title{
Deferring stenting in primary angioplasty: A critical view based on available evidence
}

\author{
Diferir la implantación de stents coronarios en la angioplastia primaria: una visión crítica \\ basada en la evidencia disponible
}

Diego Fernández-Rodríguez*, Kristian Rivera, and Juan Casanova

Department of Cardiology, Hospital Universitari Arnau de Vilanova, Institut de Recerca Biomèdica de Lleida. Lleida, Spain

We find highly interesting the work by Custodio-Sánchez et $\mathrm{al}^{1}$. on the usefulness of deferring stent implantation in patients referred for primary angioplasty $(\mathrm{PA})$ in whom high residual thrombus burden persists after the culprit lesion has been repaired.

A total of 833 patients referred for PA procedures were assessed. Patients were reclassified based on residual thrombus load after angioplasty guidewire insertion and balloon pre-dilatation and/or thromboaspiration, in those in whom a Thrombolysis in Myocardial Infarction (TIMI) Grade 2-3 flow was obtained on the artery responsible for the infarction. Of 47 patients with high residual thrombus load, 19 received immediate stent implantation, while in 28 patients, stenting was delayed, according to the operator's criteria. The deferred implant group was observed to have better myocardial perfusion indicators, assessed using the TIMI Myocardial Perfusion (TMP) scale, with stent implantation being avoided in $56 \%$ of patients, although during follow-up, no significant differences were detected between groups with regard to clinical prognosis. No more specific additional studies, such as cardiac magnetic resonance imaging, were performed for better assessment of the microcirculation state.
The benefits of a deferred stenting strategy would hypothetically consist in preserving microvasculature integrity by avoiding embolization and non-reflux associated with immediate stenting in PA. Furthermore, avoiding the use of stents in certain patients might prevent the occurrence of complications such as restenosis or stent thrombosis. However, the deferred strategy has shown conflicting results with regard to microvascular preservation in resonance studies ${ }^{2,3}$, and the main study assessing clinical events (DANAMI-3-DEFER $)^{4}$, as well as a meta-analysis of clinical trials ${ }^{5}$, failed to demonstrate benefits in hard clinical outcome variables, and even showed an association with greater need of target vessel revascularization ${ }^{4}$. These facts, together with the inherent need for recatheterization with this strategy, have led scientific societies to not endorse its routine use ${ }^{6}$.

Based on the above, we provide certain considerations:

- Sample size: The small size of the study, due to its single-center nature, and the difficulty for recruiting this type of patients, as confirmed by similar studies $^{6,7}$, did not allow multiple differences in clinical and angiographic characteristics, as well as in clinical

\section{Correspondence:}

*Diego Fernández-Rodríguez

Hospital Universitari Arnau de Vilanova

Av. Alcalde Rovira Roure, 80

Date of reception: 16-02-2019

Date of acceptance: 09-03-2019

E-mail: d.fernan.2@ hotmail.com
Available online: $30-10-2019$ Arch Cardiol Mex (Eng). 2019;89(2):187-188 www.archivoscardiologia.com the CC BY-NC-ND license (http://creativecommons.org/licenses/by-nc-nd/4.0/). 
outcomes, to be quantified as significant, which may have affected the study conclusions

- Thrombotic load reduction: Stent implantation in infarction acute phase is associated with thrombotic embolization. At present, the main strategy to reduce thrombotic load is manual thrombectomy, and despite not being routinely recommended, it is a highly useful tool in patients with high thrombotic load ${ }^{6,8}$. In this work, more than $40 \%$ of patients per group did not receive thrombectomy. This may have increased embolization and worsened myocardial perfusion, especially after immediate stent implantation

- Coronary ectasia: The authors hypothesize that the deferred strategy could be associated with implantation of larger diameter stents in the second procedure since acute vasoconstriction is reduced. However, in their data, no significant differences were observed in the diameter of the ultimately implanted stents $(4 \pm 0.7 \mathrm{~mm}$ vs. $3.7 \pm 0.7 \mathrm{~mm} ; \mathrm{p}=\mathrm{NS})$, even when the deferred strategy was associated with a higher prevalence of coronary ectasia $(57 \%$ vs. $16 \%$; $p=$ 0.005). However, we agree that, in coronary ectasia extreme cases, unavailability of stents with sufficient diameter to achieve adequate apposition could be a limitation to stent implantation in the acute phase ${ }^{9}$.

- Prevention of restenosis and stent thrombosis: The paper reports a stent implantation reduction higher than $50 \%$ in the deferred strategy group. However, this decrease did not translate into clinical benefits since the deferred strategy group showed a higher percentage of target vessel revascularization, stent thrombosis, recurrent infarction, and death, although with statistical significance not being reached, probably due to the small sample size. At present, the low rate of restenosis and thrombosis with the use of new-generation drug-eluting stents in infarction ${ }^{10}$ has reduced interest on the deferred strategy, and guidelines do not recommend its generalized use ${ }^{6}$.
One relevant contribution of the present study ${ }^{1}$ is that it describes that a deferred stenting strategy, restricted to patients with high residual thrombotic load, might be an alternative to the conventional strategy in PA. This work highlights the need to broaden the scope of research on the role of residual thrombotic load on microvascular function and long-term prognosis in these patients.

\section{References}

1. Custodio-Sánchez P, Damas-De Los Santos F, Peña-Duque MA, Coutiño-Castelán D, Arias-Sánchez E, Abundes-Velasco A, et al. Deferred versus immediate stenting in patients with ST - segment elevation myocardial infarction and residual large thrombus burden reclassified in the culprit lesion. Arch Cardiol Mex. 2018; pii: S1405-9940(18)30032-6.

2. Casse SE, Belle L, Ndrepepa G, Bosson JL, Fusaro, Lønborg, et al. Deferred vs Immediate Stenting in Primary Percutaneous Coronary Intervention: A Collaborative Meta-analysis of Randomized Trials With Cardiac Magnetic Resonance Imaging Data. Can J Cardiol. 2018;34:1573-80.

3. Carrick D, Oldroyd KG, McEntegart M, Haig C, Petrie MC, Eteiba $\mathrm{H}$, et al A randomized trial of deferred stenting versus immediate stenting to prevent no- or slow-reflow in acute ST-segment elevation myocardial infarction (DEFER-STEMI). J Am Coll Cardiol. 2014;63:2088-98.

4. Kelbaek H, Hofsten DE, Kober L, Helqvist S, Klovgaard L, Holmvang L, et al. Deferred versus conventional stent implantation in patients with ST-segment elevation myocardial infarction (DANAMI 3-DEFER): an open-label, randomized controlled trial. Lancet. 2016;387:2199-206.

5. Mahmoud AN, Saad M, Elgendy AY, Mentias A, Elgendy IY. et al. Deferred or immediate stent implantation for primary percutaneous coronary intervention: Ameta-analysis of randomized trials. Catheter Cardiovasc Interv. 2018;91:260-4

6. Ibanez B, James S, Agewall S, Antunes MJ, Bucciarelli-Ducci C, Bueno $\mathrm{H}$, et al. 2017 ESC Guidelines for the management of acute myocardial infarction in patients presenting with ST-segment elevation. Eur Heart J. 2018;39:119-77.

7. Tang $L$, Zhou $S H, H u X Q$, Fang ZF, Shen XQ. Effect of delayed vs. immediate stent implantation on myocardial perfusion and cardiac function in patients with ST-segment elevation myocardial infarction undergoing primary percutaneous intervention with thrombus aspiration. Can J Cardiol. 2011;27:541-7.

8. Ahn SG, Choi HH, Lee JH, Lee JW, Youn YJ, Yoo SY, et al. The impact of initial and residual thrombus burden on the no-reflow phenomenon in patients with ST-segment elevation myocardial infarction. Coron Artery Dis. 2015;26:245-53.

9. Schram HCF, Hemradj VV, Hermanides RS, Kedhi E, Ottervanger JP; Zwolle Myocardial Infarction Study Group. Coronary artery ectasia, an independent predictor of no-reflow after primary $\mathrm{PCl}$ for ST-elevation myocardial infarction. Int J Cardiol. 2018;265:12-7.

10. Sabaté $M$, Brugaletta $S$, Cequier A, Iñiguez A, Serra A, Jiménez-Quevedo $P$, et al. Clinical outcomes in patients with ST-segment elevation myocardial infarction treated with everolimus-eluting stents versus bare-metal stents (EXAMINATION): 5-year results of a randomised trial. Lancet. 2016;387:357-66. 